\title{
Improving the Efficiency of the Educational Process Using Interactive Teaching Methods
}

\author{
Valentin S. Nikolaenko, ${ }^{1, a}$, Elena A. Grakhova ${ }^{1}$, and Timur R. Rakhimov ${ }^{1}$ \\ ${ }^{1}$ Tomsk Polytechnic University, 634050 Lenin Avenue, 30, Tomsk, Russia
}

\begin{abstract}
This article provides a solution to the problem of comprehensibility of educational material in the process of training participants in the educational process in higher educational institutions. This problem is solved by analyzing the various forms of education and communication, such as passive, active and interactive. The article also provides a classification of interactive methods. It also presents an example of interactive teaching methods in the educational process, the author's board game «Master Risk», which is designed to enhance the practical training in the course «Management». The game simulates two procedures of risk management «Risk Identification» and «Risk Analysis». The game «Master Risk» allows participants of the educational process to enhance theoretical knowledge and practical skills in areas of project management and risk management. Introduction of the game to the educational process should improve the cognitive activity of the participants of training and help obtaining new knowledge using modern educational technologies, skills to work in a team (group) and develop professional skills as well as general cultural competences.
\end{abstract}

\section{Introduction}

Optimization of the educational process for the formation of professional and general competences is quite topical in higher educational establishments

The effectiveness of learning in higher educational establishments is influenced by many factors, such as skills to organize effective educational activities, organization of self-training, testing and monitoring of comprehensibility of educational material, etc. Simultaneous consideration of these factors creates pedagogical problems, which can be solved by modern educational methods and tools (Figure 1).

In this context, the aim of the article is to look for pedagogical tools that would increase the effectiveness of educational material retention in training of participants. To achieve this goal the following tasks have been accomplished:

1.Passive, active and interactive methods used in the educational process are analyzed;

2. The systems of classifications of passive, active and interactive methods are considered;

3. The board game «Master Risk» that imitates the basic business processes of project activities and risk management is developed.

\section{Analysis of active, passive and interactive methods}

According to the federal state educational standards, higher education shall be directed to the formation and development of the common cultural and professional competencies of the participants of education. Moreover, it should be noted that for the development of these competencies active and interactive teaching methods should be used. Let us consider these methods in detail.

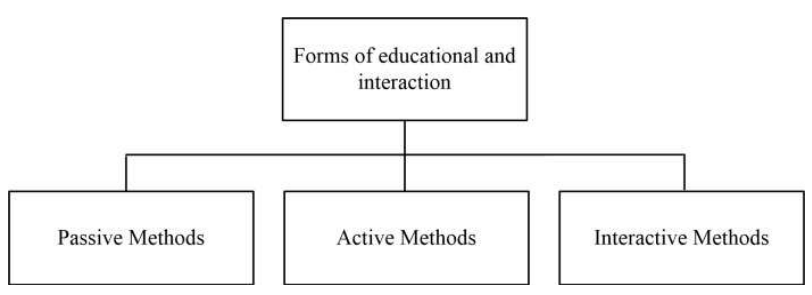

Fig. 1. Forms of training and interaction

According R. Kaspina and L. Plotnikova, interactive education is a command style of learning, where all participants of the educational process interact with each other, exchange information, jointly solve problems and make decisions [1].

\footnotetext{
a Corresponding author: nikolaenkovs@tpu.ru
} 
According to Ghica G. and Grigorescu G.J.: «Interactive teaching methods in combination with modern information technologies encourage cognitive activity, develop personal and creative potential of the participants of training; allow one to cover a large amount of educational information with a better quality of its consideration, because every action is associated with the work of the whole team» [2].

In modern pedagogy, three main types of interactivity in the educational process are considered (Figure 2).

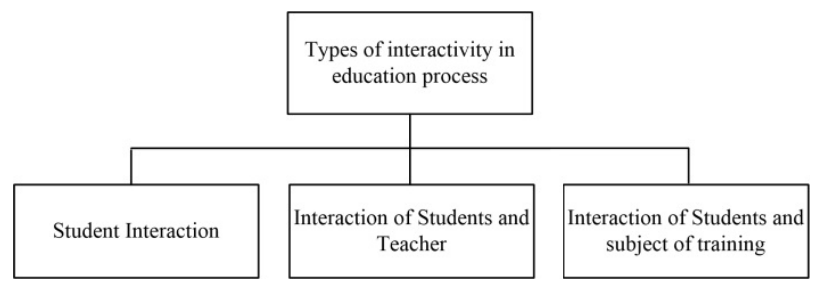

Fig. 2. Types of interactivity in the learning process

A variety of interactive methods creates a problem of their optimal combination, which would allow developing harmoniously general cultural and professional competences. According to some authors, the problem of choosing the best methods of teaching is very relevant, and its solution depends on the pedagogical situations and the individual characteristics of the educational process and abilities of the group of students [2].

In the works of Y Torkunova it is argued that the best combination is: brainstorming - $10 \%$, imitating training $10 \%$, didactic game $-10 \%$, technologies projects $-40 \%$, information and computer technologies - $20 \%$, case study $-10 \%$, laboratory research workshop - 20\% [3].

Developed by Y. Torkunova, the combination is supported by empirical data, which were obtained by Edgar Dayle [4]. According to the pyramid of learning by Dayle the comprehensibility of educational material depends on the methods used. For example, the assimilation of educational material at lectures $10 \%$, seminar - 30\%, case study - 50\%, simulations - 70\%, project-based learning, or teaching others - 90\%.

Interactive methods allow using not only the human mind, but also her/his feelings, emotions, willpower, i.e. involving "the whole man" in the learning process [5].
Studies in the United States in the 1980s, conducted by National Training Laboratories in Bethel, Maine allowed compiling data on the effectiveness of (the average percentage of learning) of different methods of teaching [6]. These results are shown in the following «Learning Pyramid» (Figure 3). They confirm the ancient wisdom, formulated in the Chinese proverb: «Tell me - and I will forget. Show me - and I will remember. Let me do it - and it will stay with me forever»!.

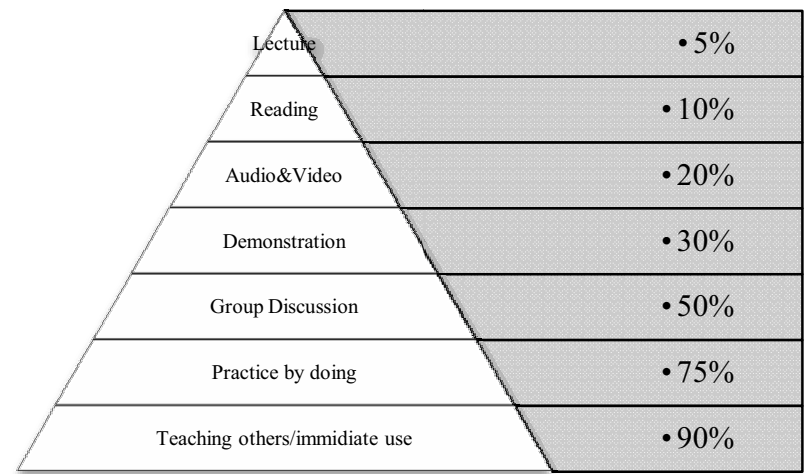

Fig. 3. The Learning Pyramid

Depending on the individual characteristics of students and teachers in a specific group and their training, results can be different, deviating from the averages, but overall, most students and teachers, agree with such average results.

\section{Classification of interactive teaching methods}

Currently, in pedagogy there is no single standard classification of interactive technologies and teaching methods. In the literature, there is a description of certain classifications (Table 1). Among the different classifications the most common and comprehensive classification is a division of interactive methods of learning into simulative and non-simulative [7]. Simulation methods, among which non-gaming technologies are more commonly used, are closely related to the use of new teaching methods in the educational process. Non-simulation methods are used in traditional forms of learning.

Table 1. Interactive technologies and methods of teaching

\begin{tabular}{|c|c|c|c|c|c|c|c|c|c|}
\hline \multirow[b]{2}{*}{ I } & \multicolumn{9}{|c|}{ Interactive technologies in education } \\
\hline & $\begin{array}{l}\text { Busi- } \\
\text { ness } \\
\text { games }\end{array}$ & $\begin{array}{l}\text { Role } \\
\text { playing }\end{array}$ & $\begin{array}{l}\text { Training } \\
\text { discussion } \\
\mathrm{S}\end{array}$ & $\begin{array}{l}\text { Brain } \\
\text { stormin } \\
\mathrm{g}\end{array}$ & $\begin{array}{l}\text { The analysis } \\
\text { of specific } \\
\text { situations }\end{array}$ & $\begin{array}{l}\text { Programme } \\
\text { d training }\end{array}$ & $\begin{array}{l}\text { Computer } \\
\text { simulation }\end{array}$ & $\begin{array}{l}\text { Group } \\
\text { discussion } \\
\mathrm{S}\end{array}$ & $\begin{array}{l}\text { Psychologic } \\
\text { al training }\end{array}$ \\
\hline & \multicolumn{9}{|c|}{ Interactive teaching methods } \\
\hline & 2.1. & \multicolumn{8}{|c|}{ NON-SIMULATIVE } \\
\hline & & \multicolumn{8}{|l|}{ Lecture } \\
\hline $\begin{array}{l}\text { I } \\
\text { I }\end{array}$ & 2.1 .1 & \multicolumn{3}{|c|}{ Problem oriented lecture } & $\begin{array}{l}\text { re with the } \\
\text { is of specific } \\
\text { ions }\end{array}$ & \multicolumn{2}{|c|}{$\begin{array}{l}\text { Lecture with a planned } \\
\text { mistake }\end{array}$} & \multicolumn{2}{|c|}{$\begin{array}{l}\text { Lecture } \\
\text { visualization }\end{array}$} \\
\hline & 2.3 .2 & \multicolumn{8}{|c|}{ Lessons (laboratory and practical) } \\
\hline & 2.1 .2 & \multicolumn{8}{|c|}{ Course project } \\
\hline
\end{tabular}




\begin{tabular}{|c|c|c|c|c|c|c|c|}
\hline 2.1 .4 & \multicolumn{7}{|c|}{ Graduate diploma projects } \\
\hline 2.2 . & \multicolumn{7}{|c|}{ SIMULATIVE } \\
\hline \multirow[b]{2}{*}{2.2 .1} & \multicolumn{7}{|c|}{ Gaming } \\
\hline & $\begin{array}{l}\text { Business } \\
\text { games }\end{array}$ & $\begin{array}{l}\text { Research } \\
\text { games }\end{array}$ & $\begin{array}{l}\text { Education } \\
\text { al games }\end{array}$ & $\begin{array}{l}\text { Brain } \\
\text { storming }\end{array}$ & \multicolumn{2}{|c|}{$\begin{array}{l}\text { Engineering } \\
\text { games }\end{array}$} & $\begin{array}{l}\text { Organizational- } \\
\text { activity games }\end{array}$ \\
\hline & \multicolumn{7}{|c|}{ Non-gaming } \\
\hline 2.2 .2 & $\begin{array}{l}\text { Discussion } \\
\mathrm{s}\end{array}$ & Case-study & $\begin{array}{l}\text { The metho } \\
\text { developing }\end{array}$ & $\begin{array}{l}\text { of } \\
\text { perations }\end{array}$ & Training & $\begin{array}{l}\text { Contact } \\
\text { training }\end{array}$ & $\begin{array}{l}\text { The method of } \\
\text { group solution of } \\
\text { creative problems } \\
\text { (Delphi method, } \\
\text { the method 6-6, } \\
\text { etc.) }\end{array}$ \\
\hline 2.3 & Webinar & & & & & & \\
\hline
\end{tabular}

\section{The game «Master Risk»}

Now let us consider the example of the training session in the subject «Management» for students of economic major, using the board game. Despite the fact that among the methods of training simulation games are used less frequently, it should be noted that the game form of training allows increasing the comprehensibility of educational material. The game often includes a group exercise to develop solutions in conditions simulating reality [8].

As an example, we will consider the board game «Master Risk», which significantly increases the comprehensibility of educational material in the learning process. «Master Risk» is a board game designed for practical training in the «Management» course. It can also be used to consolidate the theoretical knowledge in the areas of project management and risk management. The main educational goal of the game is the formation and development of the general cultural and professional competencies of the participants of training, such as:

- Understanding of the verbal and numerical scale of Harrington;

- Development of skills necessary for risk analysis, namely the skills to determine the probability and impact of risk events;

- development of skills needed for the classification of adverse risks;

- development of communication skills.

According to the rules of the game «Master Risk»" there are two teams, three players against other three. Total number of players is six. Members of these teams act as project managers who manage the project team. The game «Master Risk» simulates the life cycle of the project, where during project development a variety of risks may occur.

The game consists of two stages: «risk analysis» and «project implementation». Let us consider each of these stages in more detail.

At the stage of «Risk Analysis», participants study a list of 40 risks, which often occur in the projects. Within 45 minutes of training participants are encouraged to conduct an expert assessment of these risks, using a Harrington numerical scale (Table 2 and Table 3) and the risk matrix (Figure 4). Note that the risk matrix consists of four areas:
- the area of catastrophic risks (Tigers) - these are the risks that may have a significant impact on the

successful completion of the project, even to the extent of stopping it;

- the area of unpredictable risks (Alligators) - these are the risks that may have a significant impact on the project, but the probability of their occurrence is lower compared to the catastrophic risks;

- the area of frequently encountered risks (Puppies) - these include risks that have a high probability of occurrence, but are not able to influence significantly the successful completion of the project;

- The area of minor risks (Kittens). These risks can be ignored because they cannot have a significant adverse impact on the project and have a low probability of occurrence.

Table 2. The verbal numerical scale of Harrington to evaluate the degree of influence

\begin{tabular}{ccc}
\hline $\begin{array}{l}\text { Risk impact on the } \\
\text { project }\end{array}$ & $\begin{array}{c}\text { factor of } \\
\text { Harrington } \\
\text { according to } \\
\text { PMBoK }\end{array}$ & $\begin{array}{c}\text { factor of } \\
\text { Harrington }\end{array}$ \\
\hline Very High & $0,8-1,0$ & 5 \\
\hline High & $0,64-0,8$ & 4 \\
\hline Medium & $0,37-0,64$ & 3 \\
\hline Low & $0,2-0,37$ & 2 \\
\hline Very low & $0,0-0,2$ & 1 \\
\hline No influence & 0,0 & 0 \\
\hline
\end{tabular}

Table 3. The verbal numerical scale of Harrington to evaluate the probability of risk

\begin{tabular}{ccc}
\hline $\begin{array}{l}\text { Probability of risk } \\
\text { in the project }\end{array}$ & $\begin{array}{c}\text { Probability } \\
\text { factor }\end{array}$ & $\begin{array}{c}\text { factor of } \\
\text { Harrington }\end{array}$ \\
\hline Very High & $0,8-1,0$ & 5 \\
\hline High & $0,64-0,8$ & 4 \\
\hline Medium & $0,37-0,64$ & 3 \\
\hline Low & $0,2-0,37$ & 2 \\
\hline Very low & $0,0-0,2$ & 1 \\
\hline No probability & 0,0 & 0 \\
\hline
\end{tabular}

In the process of training participants the scale of Harrington was used and an expert assessment of the likelihood and impact of risks was conducted. Further, the participants conduct the conditional risk classification and choose seven risks, which, in their opinion, should be insured. 
The second stage of the game «Project Implementation» (45 minutes) is focused on moving down the project. After each turn, the participants take a «risk card». Each «risk card» provides information about the risk, its type, and lists the requirements that players must meet, if they have not ensured against this risk at the stage of «Risk Analysis». Thus, if players in advance protect themselves against negative, catastrophic risks, then they have a chance to successfully complete the game process, i.e. successfully complete the project.

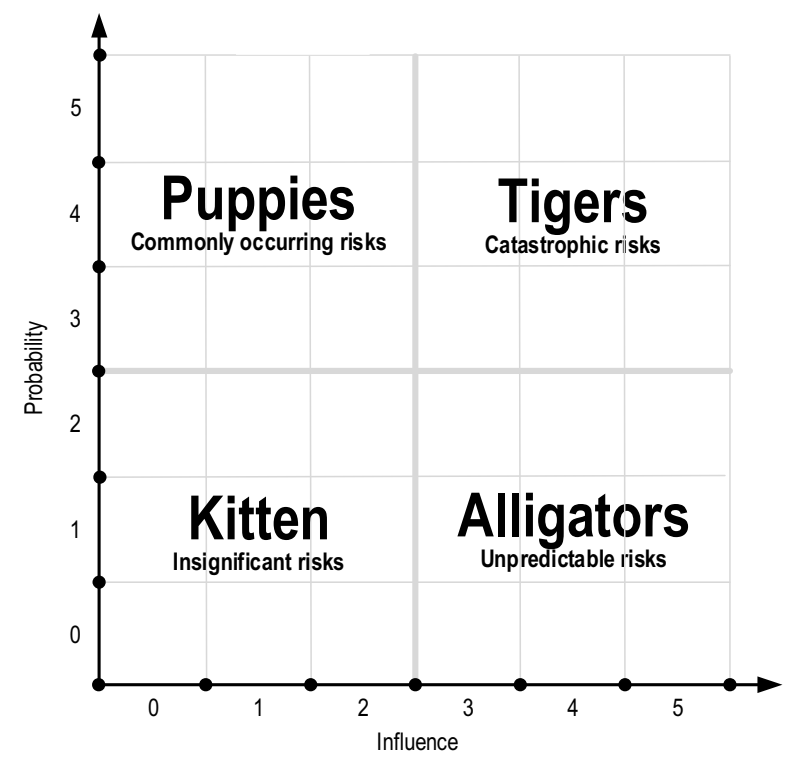

Fig. 4. The «Risk Analysis» matrix

\section{Conclusion}

Pedagogical results of the completion of the game play are:

- obtaining skills, which are necessary for the identification of risks;

- developing skills in the correct formulation of the negative risk events;

- formation of skills, which are necessary for qualitative analysis and classification of adverse risk events.

Based on obtained results, we can conclude:

1.Introduction of game tasks to the educational process improves the cognitive activity of the participants of training.

2. Exercises in the form of the game awaken the creative activity of the participants of training and their interest in the subject under study;

3. Acquisition of new knowledge using modern educational technologies and skills to work in a team (group) allow one to develop professional skills as well as general cultural competences;

4. The results of the use of interactive technologies in teaching are not only focused on acquiring of knowledge but also on developing skills for professional activity.

Overall, it should be noted that interactive teaching methods in modern conditions are very relevant. The need for the introduction of interactive teaching methods in the educational process is due to two trends. The first trend is a general direction of the development of education, which focuses not so much on obtaining specific knowledge but on development of practical skills of intellectual activity, learning skills and ability to process huge amounts of information. The second trend is connected with development of requirements for personal qualities of graduates, which should generate their optimal behavior in different situations in the professional field.

\section{References}

1. R. Kaspinaad, L. Plotnikova, Procedia - Social and Behavioral Sciences, 152, 279 (2014)

2. G. Ghica, G.J. Grigorescu, Procedia - Social and Behavioral Sciences, 116, 3588-3592 (2014)

3. Y.V. Torkunova, Procedia - Social and Behavioral Sciences, 191, 1690 (2014)

4. O.N. Petukhov, V.S. Nikolaenko, Network Projects as a New Paradigm in e-Learning. SGEM 2014 International Multidisciplinary Scientific Conferences on Social Sciences and Arts (2014).

5. A. Gutnikov, Social Education, 61, 70-74 (1997)

6. J. Lalley, R. Miller, Education and Information Technologies, 128(1), 64-79 (2007)

7. I.V. Krakovetskay, T.R. Rakhimov, V.S. Nikolaenko, The Concept of Virtual Education Environment Based on the Principles of Education 2.0, Web 2.0 and Project Activities. The Triple Helix XII International Conference "Triple Helix and Innovation-Based Economic Growth: New Frontiers and Solutions» (2014)

8. R. Duke, J. Geurts, Policy Games for Strategic Management; Pathways into the Unknown. The Magic Circle: Principles of Gaming \& Simulation (Rotterdam: Sense Publishers, 2006) 